Pak. j. sci. ind. res. Ser. B: biol. sci. 2019 62B(3) 172-177

\title{
Detection of Food Poisoning (Bacillus cereus) Pathogen in Cooked and Refrigerated Rice Samples
}

\author{
Anila Sidiqui, Shagufta Ambreen Shaikh*, Shagufta Naz and Seema Ismat \\ FMRRC, PCSIR Laboratories Complex Karachi, Karachi-75280, Pakistan \\ (received November 11, 2017; revised April 27, 2018; accepted June 7, 2018)
}

\begin{abstract}
Rice is a staple food of Pakistan. It is being contaminated with several food poisoning causing bacterial and mold contaminants. In this study 100 different rice samples were collected from local market of Karachi city. The presence of Bacillus cereus vegetative cell and survival of their spores were quantitavely analyzed after cooking and refrigeration. From the study it was observed that out of 100 rice samples, $25 \%$ cooked/refrigerated samples were positive for the presence of B.cereus spores, even there were few samples which showed increase of count due to improper (cooking and refrigeration ) which causes the germination and proliferation of spores into vegetative cells under favorable conditions. The detection of increased count of $B$. cereus even after cooking and refrigeration treatments is very alarming since cooking is supposed to be best treatment given to the raw food. Different rice dishes are being frequently consumed by the general population and are also available on different shops (as biryanis or fried rice), hence, detection of $B$. cereus in cooked rice samples will be useful to control any outbreak of food poisoning cases especially in summer seasons.
\end{abstract}

Keywords: Bacillus cereus, food poisoning, cereulide toxin, rice sample

\section{Introduction}

Microbiological analysis of cereal grains which includes total count of molds, yeast, Escherichia coli, Bacillus cereus and Salmonella sp. is usually carried out to determine the hygienic conditions/quality of rice, which gets contaminated during growth, harvesting and processing (Haque and Russell 2005; Anderson, 1995). Usually endospore forming bacteria, yeast and mold are considered as normal flora of rice besides Aspergillus sp., which has also become frequent contaminant of rice due to heavy rain in eastern, south and western regions of Pakistan.

According to Rajkovic et al. (2006) rice is frequently associated with B.cereus related food poisonings. $B$. cereus is an endospore-forming, gram positive, facultative anaerobe which is commonly isolated from food, which produces various virulent factors or enterotoxins. B.cereus is known to cause two types of foodborne diseases namely diarrhoea and emesis. Diarrhoeal disease is associated with edible items and has an incubation period of 8-16 h. Symptoms associated with diarrhoea include abdominal pain and severe watery diarrhoea (Kramer and Gilbert, 1989). The diarrhoeal enterotoxins are produced at an optimum temperature

*Author for correspondence;

E-mail: shagufta.a.shaikh@gmail.com of $32{ }^{\circ} \mathrm{C}$ to $37^{\circ} \mathrm{C}$, it adapts well in a wide range of $\mathrm{pH}$ from 4.9-9.3 and salt concentration up to 7.5\% (Batt and Tortorello, 2014). It resembles the foodborne illness caused by Clostridium perfringens (Ankolekar et al., 2009).

While the emetic type is parallel to Staphylococcus aureus food poisoning and is linked to farinaceous foods especially cooked rice. Nausea, vomiting and malaise are the symptoms of the emetic disease which occurs rapidly (0.5-5 h) after consumption of contaminated food. B.cereus can grow quickly and produces emetic toxins in very short period of time in cooked and other ready to eat foods at room temperature (Agata et al., 2002). The emetic type illness is characterized by nausea and vomiting starting after $\leq 1$ to 5 due to consumption of rice which is rich in starch content. Variety of foods including cooked meat, poultry and dishes which are rich in protein contents and involved in diarrhoeal type of illness (Clavel, 2004; Lund, 1996).

According to Koohy-Kamaly-Dehkordy et al. (2013) the spices could also contaminate the food. Naeumayr et al. (1983) has found that B.cereus spores make up $50 \%$ of mesophilic aerobic plate counts in spices. This is because spores could survive the drying process and long storage conditions (ICMSF, 2005). Many foods such as gravies, sauces, or stews can be contaminated 
due to the added spices which are store houses for spore forming bacteria, and under favorable conditions, they germinate, proliferate and sometimes also produce enterotoxins (Banerjee and Sarkar, 2003). B.cereus in its spore and vegetative forms, is widely found in soil. Spices or rice contaminated with spores of $B$. cereus had also been a cause of several outbreaks of the diarrhoeal syndrome in Hungary during 1960's. The spores in spices and other food items could survive cooking temperatures which germinates when cooled improperly, and the nutrients in dish support the growth of the resulting vegetative cells (Kramer and Gilbert, 1989).

Rice is the most consumed cereal in the world and has been reported as an important factor in food poisoning caused by B. cereus (Granum, 2000). The preparation of many rice dishes requires the addition of spices during cooking and right after cooking, which makes it logical to test the growth of $B$. cereus (spores) in rice before and after cooking.

It is important for the restaurant and food market to provide safe foods to consumers. The aim of this study is to evaluate the incidence of $B$. cereus in various rice samples collected from the local markets of metropolitan city. The survival of $B$. cereus spores after heating or refrigerating treatments of the cooked rice samples was further investigated.

\section{Materials and Methods}

Procurement of sample. 100 different rice samples were collected from the local markets of Karachi which includes branded and local samples.

Sample preparation. 50 gram of each sample aseptically weighed and mixed in $450 \mathrm{~mL}$ of phosphate buffer and blended for $2 \mathrm{~min}$ at $18000 \mathrm{rpm}$. This gives 1:10 dilution, and then further serial dilutions were made.

Enumeration of B.cereus. Spread plate method was used for the enumeration of B.cereus. For this purpose $0.1 \mathrm{~mL}$ of each dilution was evenly spread by using sterile glass rod spreader over the surface of pre-poured MYP agar plates in duplicate. Plates were incubated at $30{ }^{\circ} \mathrm{C}$ for $24-48 \mathrm{~h}$.

Positive and negative control of MYP agar positive control. B cereus (ATCC 11778) was streaked on MYP agar plate. Plates were incubated at $30^{\circ} \mathrm{C}$ (pink coloured colonies with egg yolk precipitation) (Fig. 1).
Negative control. E. coli (ATCC 25922) was streaked on MYP agar plate. Plates were incubated at $30^{\circ} \mathrm{C}$ for $24 \mathrm{~h}$ (no growth was observed).

Identification of B.cereus on MYP agar. B.cereus appeared as pink coloured colonies surrounded by zone of precipitation on MYP agar plates after $24 \mathrm{~h}$. Plates with no growth were re-incubated for additional $24 \mathrm{~h}$.

Confirmation of B.cereus. In order to confirm the presence of B.cereus the suspected colonies were picked from MYP agar plates and subjected to different confirmatory tests including microscopy, catalase test, anaerobic utilization of glucose, nitrate reduction, VP reaction and Mannitol fermentation (Table 1).

Cooked sample testing. After analyzing the samples for the presence of vegetative forms, the samples were cooked for twenty minutes and cooled at room temperature and then the samples were analyzed for the presence of spore by the Schaeffer-Fulton staining method and agar plating on MYP medium.

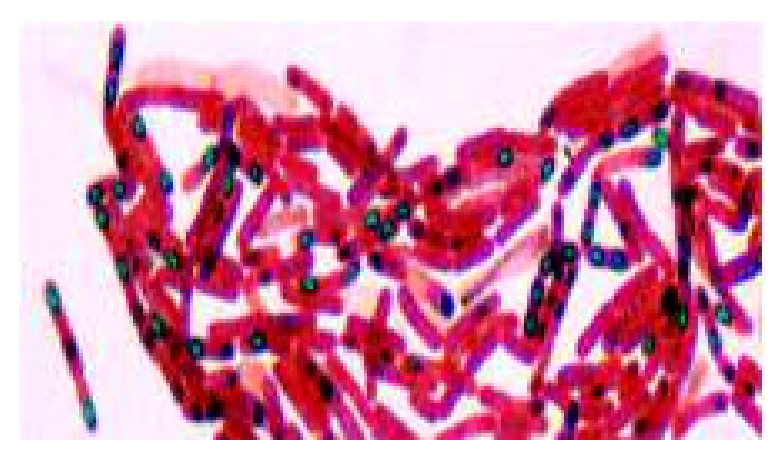

Fig. 1. Picture of vegetative cells with spores of B. cereus.

Table 1. Identification test results of suspected Bacillus cereus strains

\begin{tabular}{|c|c|}
\hline Test performed & Result obtained \\
\hline Gram reaction & Gram positive rods with spores \\
\hline Glucose fermentation & $\begin{array}{l}\text { Ferments glucose and produces } \\
\text { acid anaerobically }\end{array}$ \\
\hline Nitrate reduction & Reduces nitrate to nitrite \\
\hline VP test & Positive \\
\hline Mannitol fermentation test & Negative \\
\hline
\end{tabular}


Refrigerated sample testing. The cooked samples of rice were left at room temperature for 4-6 $\mathrm{h}$ and then the samples were refrigerated for $24 \mathrm{~h}$. Next day the samples were again tested for the surviving B.cereus spores by the Schaeffer-Fulton staining method and agar plating on MYP medium.

\section{Results and Discussion}

100 different rice samples including local and branded, were qualitatively and quantitatively analyzed after passing through different traditional treatments which includes cooking and refrigeration, respectively. It can be observed from the data shown in Table 2 that even after cooking $25 \%$ of the samples were detected with the presence of B.cereus (spores) and were not fit for human consumption. There are few samples (sample \# $8,12,19,21$ and 25) which gave increased count even after heating and refrigeration as compared to raw samples. It was due to the regrowth of the survived spores which in the presence of favorable growth conditions such as temperature $\left(35^{\circ} \mathrm{C}\right)$ germinate and propagate very quickly and gave high count in the following samples.

Among $25 \%$ of cooked and refrigerated rice samples, $96 \%$ cooked samples showed the count of B. cereus below $105 \mathrm{cfu} / \mathrm{g}$, while among refrigerated samples $92 \%$ of the sample gave positive $B$. cereus growth below $105 \mathrm{cfu} / \mathrm{g}$. While $4 \%$ of cooked and $8 \%$ of refrigerated rice samples showed more than $105 \mathrm{cfu} / \mathrm{g}$ count. The detection of such large count of B.cereus spores in cooked and refrigerated rice samples, which has already been given conventional treatments, is very alarming because, rice dishes are very popular in Pakistan and other countries. The same survival and regeneration of B.cereus spores after giving ultrapasteurization (138 ${ }^{\circ} \mathrm{C}$ for $2 \mathrm{~s}$ ), "superpasteurization" $\left(96{ }^{\circ} \mathrm{C}\right.$ for $\left.13 \mathrm{~s}\right)$ was

Table 2. Count of B. cereus strains (with spores) in raw, cooked and refrigerated samples.

\begin{tabular}{llclcl}
\hline \hline $\begin{array}{l}\text { Rice } \\
\text { Sample }\end{array}$ & $\begin{array}{l}\leq 10^{5} \mathrm{cfu} / \mathrm{g} \\
\text { out of } 25 \\
\text { detected samples }\end{array}$ & $\begin{array}{l}\geq 10^{5} \mathrm{cfu} / \mathrm{g} \\
\text { out of } 25\end{array}$ & $\begin{array}{l}\text { Not } \\
\text { detected samples }\end{array}$ \\
\hline Raw & 17 & $68 \%$ & 8 & $32 \%$ & $75 \%$ \\
Cooked & 24 & $96 \%$ & 1 & $4 \%$ & $75 \%$ \\
Refrigerated & 23 & $92 \%$ & 2 & $8 \%$ & $75 \%$ \\
\hline \hline
\end{tabular}

also reported by Georgiana et al. (2009) in a study conducted on milk samples. It was reported by the author that the pasteurization temperature only inhibits the regrowth of B.cereus spores for 2 weeks at refrigerated temperature in highly sterilized conditions and under re contamination conditions the chances of regrowth of spores is very high along with toxin production.

The emetic type of illness is caused by consumption of rice contaminated with B.cereus toxin which is known as cereulide. It is heat stable even at $121{ }^{\circ} \mathrm{C}$ for $90 \mathrm{~min}$. $\mathrm{pH}$ stable range from 2-11, resistant to proteolysis and not antigenic (Ankolekar et al., 2009) while according to Clavel et al. (2004) the lower count of B. cereus spores are required to cause diarrhoeal disease as compared to vegetative cells because the spores can survive in the gastric acid. Furthermore, according to Gilbert (1986) $103 \mathrm{cfu} / \mathrm{g}$ is the minimum range of B.cereus cells which produces sufficient emetic toxins to cause disease. Due to this reason the presence of B.cereus in the cooked and refrigerated foods are more important to be detected than in the raw food since the survived toxin present in the food could cause the illness.

Many outbreaks are reported in the past several years due to food poisoning caused by $B$. cereus spp. It is reported to be the third main reason of food poisoning cases in the world. For example according to Granum (1994) the lowest count $2 \times 102 \mathrm{cfu} / \mathrm{g}$ of B.cereus spores was found in the food which caused outbreak of food poisoning in Norway, 117 outbreaks were reported in Hungry between 1960-1968, 50 outbreaks in Finland, 11 outbreaks in Netherland and 09 were recorded in Canada (Shinagawa1990; Gilbert 1979); USA (Bean and Griffin, 1990); UK, Scandinavia, Japan (Johnson et al., 1984) and Norway (Kotiranta et al., 2000). were also among the list of such food born outbreaks. Among normal population, elderly people or people suffering from severe diseases are more at risk to get infected with these food borne pathogens. According to Jaaskelainen et al. (2003) $<8 \mu \mathrm{g} / \mathrm{kg}$ of body weight of cereulide toxin is required to cause serious outbreaks of emetic disease. While in European Union 14\% of foods born out breaks were related to Bacillus species which also includes non-cereus, Bacillus species (EFSA, 2006). In 1992-2006 around 45 gastroenteritis cases were reported to health protection agencies caused by 
Bacillus cereus species. Mehler et al. (1997) and Dierick et al. (2005) has reported the death of 17 year old Swiss boy and 07 years old Belgian girl due to liver failure caused by emetic food poisoning. According to Rajkovic et al. (2008), Cereulide the emetic toxin of Bacillus cereus is very heat stable even at 121 and $150{ }^{\circ} \mathrm{C}$ and under high alkaline conditions the inactive toxin can revert back to cause toxic effect while its inactivation time depends upon the concentration of the toxin present in the food. The more the concentration of toxin present, the more heating time is required to make toxin inactive. It is also reported to cause cellular damage and known to inhibit human natural killer cells of immune system (Paananen et al., 2002; Shinagawa et al., 1996). Usually diarrhoeal syndrome is related to meat, sauce and dairy products which are caused by three complex heat labile protein toxins. Usually B.cereus food poisoning is not easily distinguished from those caused by $S$. aureus intoxication. According to Stenforns et al. (2007) B. cereus diarrhoeal disease shows the same symptoms as C. perfringens type A food poisoning.

In a study conducted by Tahir (2012) it was reported that the rice samples collected from local markets of Lahore city were having heavy bacterial and mold contaminations which include Aspegillus sp due to the presence of high moisture content. This finding drew attention of agriculture authorities towards any untoward catastrophe related to this import quality agriculture commodity of Pakistan. Daily Times has reported that more than 250 flood victims in relief camp of Pakistan got severe food poisoning caused by B.cereus immediately after eating cooked rice provided to them in September (2010). Mohammad Saeed et al. (2007) has also reported severe outbreak of food poisoning caused by B.cereus to which out of 110 persons, 57 were severely ill during lunch in Pakistan Army Training Center within 3-5 h of incubation period.

Recently Maria et al. (2011) has reported sudden death of a 20 year old man after consuming meal of leftover of spaghetti with tomato sauce. From the clinical findings of food samples, significant count of $9.5 \times 107 \mathrm{cfu} / \mathrm{mL}$ of $B$. cereus was found, the illness was of emetic type as cereulid toxin was percent in significant amount in the food.

\section{Conclusion}

From the qualitative and quantitative analysis of raw, cooked and refrigerated rice samples for the presence of $B$. cereus, it can be concluded that the presence of B. cereus (spores/vegetative cells) especially in the cooked and refrigerated rice samples is very alarming. As the hygiene level of our society is already very low, there are more chances of any outbreak of food poisoning among general population even causing deaths of several people.

Proper measures must be taken by goverment food departments to keep track of B.cereus (vegetative/spores) especially in ready to eat food items such as biryanis, and other foods being sold in the markets so that any sudden outbreaks could be avoided. Now-a-days there is an increased trend of using ready to eat foods from different restaurants or food outlets which could be a possible source of any outbreak in the metropolitan city. Beside this, it is also important to mention that food should also be cooked properly and should not be left at room temperature as this may cause re-growth of survived spores of bacterial strains including B.cereus, resulting in production of toxins which may cause mild nausea to severe diarrhoea leading to sudden death.

Conflict of Interest. The authors declare no conflict of interest.

\section{References}

Ankolekar, C., Rahmati, T., Labbe, R.G. 2009. Detection of toxigenic Bacillus cereus and Bacillus thuringiensis spores in US rice. International Journal of Food Microbiology, 128: 460-466.

EFSA, 2006. The community summary report on trends and sources of zoonoses, zoonotic agents, antimicrobial resistance and food borne outbreaks in the European Union in 2006. EFSA Journal, 94: 2-228.

Agata, N., Ohta, M., Yokoyama, K. 2002. Production of Bacillus cereus emetic toxin (cereulide) in various foods. International Journal of Food Microbiology, 73: 23-27.

Anderson, A.R., Onner, U., Andersson, A., Rnner, U., Granum, P.E. 1995. What problems does the food industry have with the spore-forming pathogens Bacillus cereus and Clostridium perfringens. 
International Journal of Food Microbiology, 28: 145-155.

Batt, C.A., Tortorella, M. 2014. Encyclopedia of Food Microbiology. $2^{\text {nd }}$ edition, London: Elsevier, the Netherlands.

Banerjee, M., Sarkar, P.K. 2003. Microbiological quality of some retail species in India. Food Research International, 36: 469-474.

Bean, N.H., Griffin, P.M. 1990. Foodborne disease outbreaks in the United States, 1973-1987: pathogens, vehicles and trends. Journal of Food Protection, 53: 804-817.

Clavel, T., Carlin, F., Lairon, D., Nguyen-The, C., Schmitt, P. 2004. Survival of Bacillus cereus spores and vegetative cells in acid media simulating human stomach. Journal of Applied Microbiology, 97: 214-219.

Dierick, K., Van Coillie, E., Swiecicka, I., Meyfroidt, G., Devlieger, H., Meulemans, A., Hoedemaekers, G., Fourie, L., Heyndrickx, M., Mahillon, J. 2005. Fatal family outbreak of Bacillus cereus associated food poisoning. Journal of Clinical Microbiology, 43: 4277-4279.

Granum, P.E., Baird-Parker, T.C. 2000. Bacillus species. In: BM, Lund TC, Baird-Parker GW Gould (eds.) pp. 1029-1039. The Microbiological Safety and Quality of Food. Aspen Publishers, New York, USA.

Georglana, S.B., Aires, Eduardo, H.M., Walter, Vele' Ria, C.A., Junqueira, Salvador, M. Roig, Andjose' A. F. Faria. 2009. Bacillus cereus in Refrigerated milk submitted to different heat treatments, Journal of Food Protection, 72: 1301-1305

Granum, P.E. 1994. Bacillus cereus and its toxins. Journal of Applied Bacteriology Symposium Supplement, 76: 613-663.

Gilbert, R.J., Kramer, J.M. 1986. Bacillus cereus food poisoning. Progress in Food Safety (Proceedings of Symposium). (Cliver DC \& Cochrane BA, eds), pp. 85-93. Food Research Institute, University of Wisconsin-Madison, Madison, WI, USA.

Gilbert, R.J. 1979. B. cereus gastroenteritis. In: Reimann $\mathrm{H}$, Bryan FL (eds) Food-borne infections and intoxications, pp. 495, $2^{\text {nd }}$ edition, Academic Press, Inc, New York, USA.

ICMSF, 2005. Spices, dry soups, and oriental flavorings. In: Microorganisms in Foods 6: Microbial Ecology of Food Commodities. International Commission on Microbiological Specifications for Foods. Kluwer Academic, New York, USA.

Jaaskelainen, E.L., Teplova, V., Andersson, M.A., Andersson, L.C., Tammela, P., Andersson, M.C., Pirhonen, T.I., Saris, N.E., Vuorela, P., SalkinojaSalonen, M.S. 2003. In-vitro assay for human toxicity of cereulide, the emetic mitochondrial toxin produced by food poisoning Bacillus cereus. Toxicology In Vitro, 17: 737-744.

Johnson, D.A., Aulicino, P.L., Newby, J.G. 1984. B. cereus induced myonecrosis. Journal of Trauma 24: 267-270.

Koohy-Kamaly-Dehkordy, P., Nikoopour, H., Siavoshi, F., Koushki, M., Abadi, A. 2013. Microbiological Quality of Retail Spices in Tehran, Iran. Journal of Food Protection, 76: 843-848.

Kotiranta, A., Lounatmaa, K., Haapasalo, M. 2000. Epidemiology, pathogenesis of B. cereus infections. Microbes Infection, 2: 189-198.

Lund, T., Granum, P.E. 1996. Characterization of a nonhaemolytic enterotoxin complex from Bacillus cereus isolated after a food borne outbreak. FEMS Microbiology Letters, 141: 151-156.

Muhammad, S.S., Nadeem, S.F. 2007. Epidemiological investigation of an outbreak of food poisoning traced to yogurt among personnel of a military training center. Pakitan Armed Forces Medical Journal, 57: 194-200.

Mahler, H., Pasi, A., Kramer, J.M., Schulte, P., Scoging, A.C., Bar, W., Krahenbuhl, S. 1997. Fulminax liver failure in association with the emetic toxin of Bacillus cereus. The New England Journal of Medicine, 336: 1142-1148.

María, N., Sarah, D., Nadine, D., Laurence, B., Jean, V., Jacques, W., Nicolas, S., Ronald, B., Karin, R.S., Jacques, M., Katelijne, D. 2011. Sudden death of a young adult associated with Bacillus cereus food poisoning. Journal of Clinical Microbiology, 49: 4379-4381.

Paananen, A., Mikkola, R., Sareneva, T., Matikainen, S., Hess, M., Andersson, M., Julkunen, I., SalkinojaSalonen, M.S., Timonen, T. 2002. Inhibition of human natural killer cell activity by cereulide, an emetic toxin from Bacillus cereus. Clinical \& Experimental Immunology, 129: 420-428.

Rajkovic, A., Uyttendaele, M., Vermeulen, A., Andjelkovic, M. Fitz-James, I., in 't Veld, P., Denon, Q., Ve'rhe, R., Debevere, J. 2008. Heat resistance 
of Bacillus cereus emetic toxin, cereulide. Letters in Applied Microbiology, 46: 536-541.

Rajkovic, A., Uyttendaele, M., Ombregt S.A., Jaaskelainen, E., Salkinoja-Salonen, M., Debevere, J. 2006. Influence of type of food on the kinetics and overall production of Bacillus cereus emetic toxin. Journal of Food Protection, 69: 847-852.

Shinagawa, K., Ueno, Y., Hu, D., Ueda, S., Sugii, S. 1996. Mouse lethal activity of a HEp-2 vacuolation factor, cereulide, produced by Bacillus cereus isolated from vomiting-type food poisoning. Journal of Veterinary Medical Science, 58: 10271029.
Stenfors, A.L.P., O’Sullivan, K., Granum, P.E. 2007. Food poisoning potential of Bacillus cereus strains from Norwegian dairies. International Journal of Food Microbiology, 116: 292-296.

Shinagawa, K. 1990. Purification and characterization of B. cereus enterotoxin and its application to diagnosis. In: Microbial Toxins in Foods and Feeds, A.E. Pohland et al. (eds.). pp 181-193, Springer, MA, USA.

Tahir, A., Hameed, I., Aftab, M., Bushra, M. 2012. Microbial assessment of uncooked and cooked rice samples available in local markets of Lahore. Pakistan Journal of Botany, 44: 267-270. 